\title{
Fire and Invasive Species Management in Hot Deserts: Resources, Strategies, Tactics, and Response
}

\section{By Alix Rogstad, Travis M. Bean, Aaryn Olsson, and Grant M. Casady}

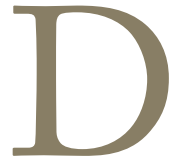

eserts cover about one-fifth of the earth's surface and occur where rainfall is less than 19 inches $(50 \mathrm{~cm})$ per year. Most deserts have specialized fauna that have evolved in tandem with specialized vegetation, and soils often have abundant nutrients but are water-limited. Ecologists have long acknowledged that once invasive species are established in these ecosystems, they have the ability to displace native plant and animal species, disrupt nutrient and fire cycles, and alter the character of the community by enhancing additional invasions. ${ }^{1-5}$

For the purposes of the Wildfire and Invasive Plants in American Deserts conference that was held in Reno, Nevada, in December 2008, North American deserts that occur at low latitudes were grouped as "hot deserts," and include the Chihuahuan, Mojave, and Sonoran deserts of the American Southwest. These three deserts share common species such as creosote bush (Larrea tridentata [DC.] Coville), ocotillo (Fouquieria splendens Engelm.), and native bunch grasses (Bouteloua spp., Aristida spp., Mublenbergia spp., etc.) that are negatively impacted by wildfires driven by invasive species. Although similarities exist, these deserts also have unique features and issues that can make land management challenging, especially in light of invasive species and largescale wildfires moving across landscapes that are not adapted to fire.

\section{Chihuahuan Desert}

Covering nearly 250,000 square miles $\left(647,500 \mathrm{~km}^{2}\right)$, the Chihuahuan Desert is the largest of the North American deserts, and is considered to be one of the most biologically diverse arid regions in the world. ${ }^{6}$ It receives most of its precipitation in the summer and the northern reaches in southern New Mexico and southeastern Arizona are considerably colder than areas to the south. Largely because of its isolated location from other regions by Mexico's two great mountain ranges, it has developed into one of the three most biologically rich deserts in the world, with up to 1,000 species adapted to that area. The Chihuahuan Desert stretches from extreme eastern Arizona to southern New Mexico through the Rio Grande drainage of west Texas/ northern Mexico and spreads southward over the Mexican Plateau into the states of Chihuahua, Coahuila, southwestern Nuevo Leon, northeastern Durango, and San Luis Potosí. The desert is bounded to the east and west by the ranges of the Sierra Madre Oriental and the Sierra Madre Occidental, respectively. The northern and southern boundaries, more difficult to define, are usually based on such diagnostic indicators as climate, vegetation, or animal communities. ${ }^{6}$ Two features that make the Chihuahuan Desert region unique are the vast temperate grasslands that skirt the mountain flanks at mid-elevation and the diversity of

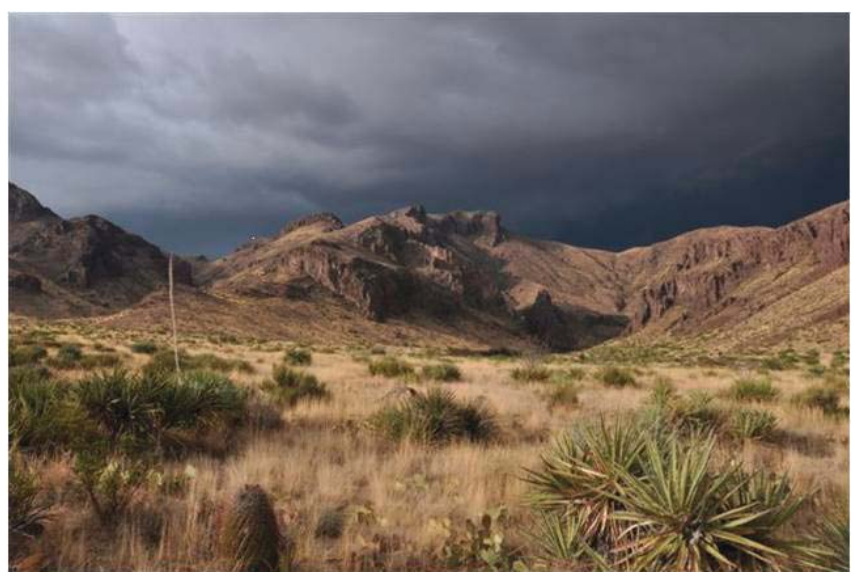

Black grama and yucca grassland, Chihuahuan Desert, near Las Cruces, New Mexico, USA. Photo courtesy of Ed L. Fredrickson, USDAAgricultural Research Service, Las Cruces, New Mexico. 
yuccas and agaves. One of the agaves, lechuguilla (Agave lechuguilla Torr.), is considered the primary diagnostic species of the Chihuahuan Desert. ${ }^{6}$

The northernmost reaches of the Chihuahuan Desert in southern New Mexico and southeastern Arizona could be classified mostly as desert grassland, dominated by $\mathrm{C}_{4}$, summer-flowering annual and perennial grasses that were stable in comparison and extent across the last glacialinterglacial cycle. ${ }^{7}$ Subtropical shrubs such as acacias (Acacia spp.), creosote bush, and mesquite (Prosopis spp.) began encroaching into this grassland within the past $\sim 5,000$ years, ${ }^{7}$ and this encroachment appears to have accelerated with livestock grazing and fire suppression in the modern era. ${ }^{8-12}$ The exact cause of this shift is debated, but probable causes include livestock grazing, climate change, and fire suppression. ${ }^{13}$ Grassland conversion and habitat fragmentation have caused increased runoff and erosion, decreased biological diversity through isolation, reduced carrying capacity, ${ }^{14}$ shifts in avian species assemblages, increased invasion by nonnative species, and decreased livestock and wildlife forage. ${ }^{10,15,16}$

Little is known about the extent of nonnative invasive species in the Chihuahuan Desert. Nonnative species of greatest concern currently include giant reed (Arundo donax L.), Bermuda grass (Cynodon dactylon [L.] Pers.), Lehmann lovegrass (Eragrostis lehmanniana Nees), buffelgrass (Pennisetum ciliare [L.] Link), Johnson grass (Sorghum halepense [L.] Pers.), and saltcedar (Tamarix spp.). At Big Bend National Park in West Texas, bioclimatic modeling, early detection protocols, and identifiers of vectors and pathways are informing management strategies for these invasive species. ${ }^{17}$ In New Mexico, one concern is that common buffelgrass, or its cold resistant variety 'Frio,' could expand northward along the Rio Grande River with regional warming.

\section{Mojave Desert}

The Mojave Desert occupies a significant portion of southeastern California and smaller parts of southern Nevada, northwestern Arizona, and extreme southwestern Utah. It occupies over 25,000 square miles $\left(64,750 \mathrm{~km}^{2}\right)$ in a typical Basin and Range topography, and elevations range from -282 feet $(-86 \mathrm{~m})$ to over 11,000 feet $(3,353 \mathrm{~m})$. Situated between the Great Basin Desert to the north and the Sonoran Desert to the south (mainly between lat $34^{\circ} \mathrm{N}$ and lat $38^{\circ} \mathrm{N}$ ), the Mojave is defined by a combination of latitude, elevation, geology, and indicator plants. This desert is believed to support between 1,750 and 2,000 species of plants, and the Joshua tree (Yucca brevifolia Engelm.) is considered an indicator species. ${ }^{18}$ Topographic boundaries include the Tehachapi together with the San Gabriel and San Bernardino mountain ranges, which are outlined by the two largest faults in California: the San Andreas and the Garlock. One key feature of this desert is that it receives most of its average annual rainfall of 5 inches $(12.7 \mathrm{~cm})$ in the winter. ${ }^{18}$

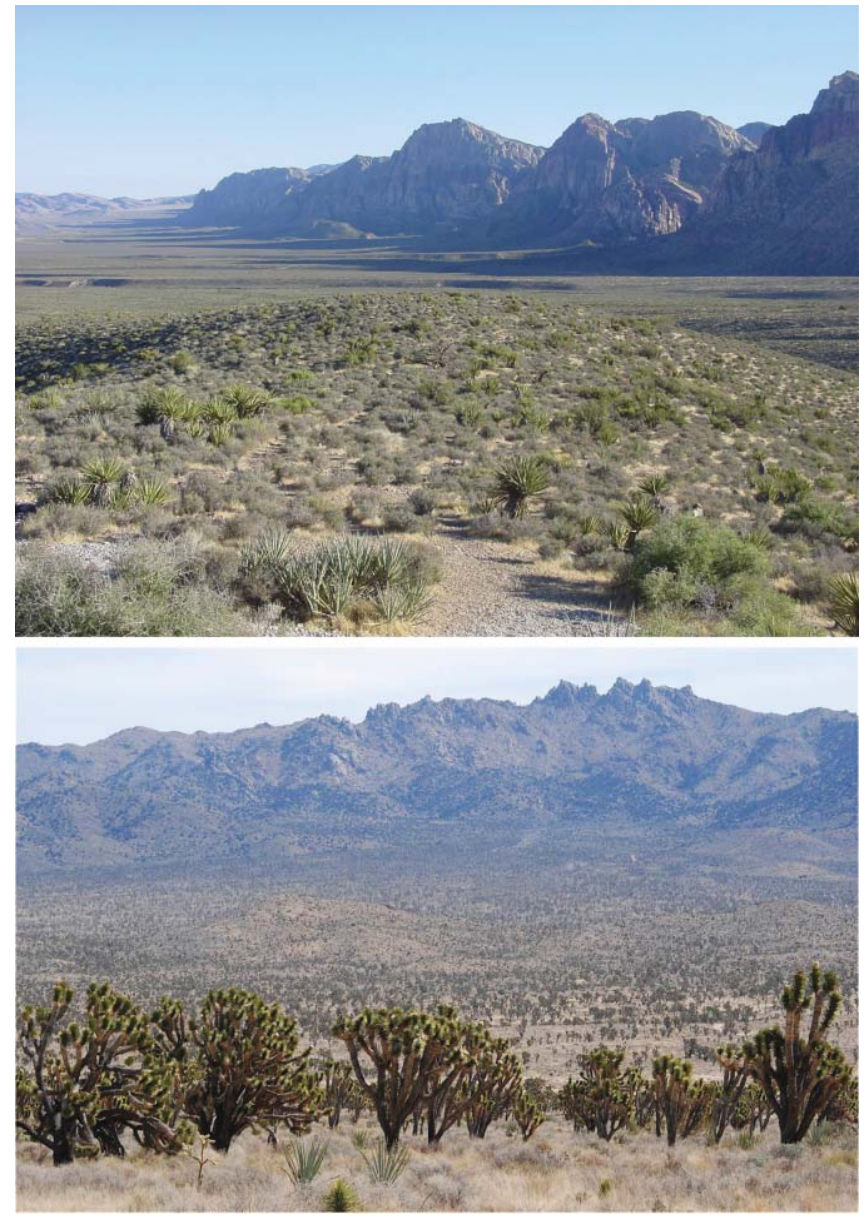

(top) Mojave Desert near Red Rock Canyon, Nevada. Photo courtesy of John Mioduszewski, Rutgers University, Piscataway, New Jersey. (bottom) Mojave National Preserve, Mojave Desert, near Cima, California. Photo depicts the upper end of the Mojave Desert where grass invasions are taking place. Photo courtesy of Todd Esque, US Geological Survey, and John Rotenberry, University of California, Riverside, California.

Ecologists have noted that since the 1970s, nonnative grasses have invaded the Mojave Desert and are now prominent in most native plant communities. ${ }^{19}$ Increased levels of soil nutrients typically have a positive effect on annual plants, especially in low-nutrient environments such as the Mojave Desert. It has been suggested that nonnative annual plants may utilize available resources more rapidly and effectively than their native counterparts, thereby allowing them an advantage over native species. ${ }^{20}$ The presence of nonnative species has a dramatic effect on wildfire potential. Historically, wildfires rarely occurred in the Mojave Desert because of limited herbaceous vegetation in the interspaces between shrubs that prevented fire spread. The invasion of species that rapidly respond to available resources and fill in the gaps between shrubs now provides continuous fuel for fires. Species of greatest concern include nonnative annual grasses (Bromus spp. and Schismus spp.), Sahara mustard (Brassica tournefortii Gouan), perennial pepperweed (Lepidium latifolium L.), and saltcedar. 


\section{Sonoran Desert}

The Sonoran Desert is a region covering 120,000 square miles $\left(311,000 \mathrm{~km}^{2}\right)$ in southwestern Arizona and southeastern California, as well as most of Baja California del Norte, the islands of the Gulf of California, and the western half of Sonora, Mexico. It is considered the wettest desert in the world, receiving up to 25 inches $(64 \mathrm{~cm})$ per year in some locations. However, the Desierto de Altar, in western Sonora, is one of the driest areas in North America, with periods of drought that can last for 30 months. ${ }^{21}$ The Sonoran Desert is the hottest of the North American deserts, and a distinctly bimodal rainfall pattern produces the most biologically diverse desert in the world, with more than 2,000 native plant species and 600+ species of animals. ${ }^{22,23}$ The desert contains a variety of unique plants and animals, such as the giant saguaro cactus (Carnegiea gigantea [Engelm.] Britton \& Rose) and the ironwood tree
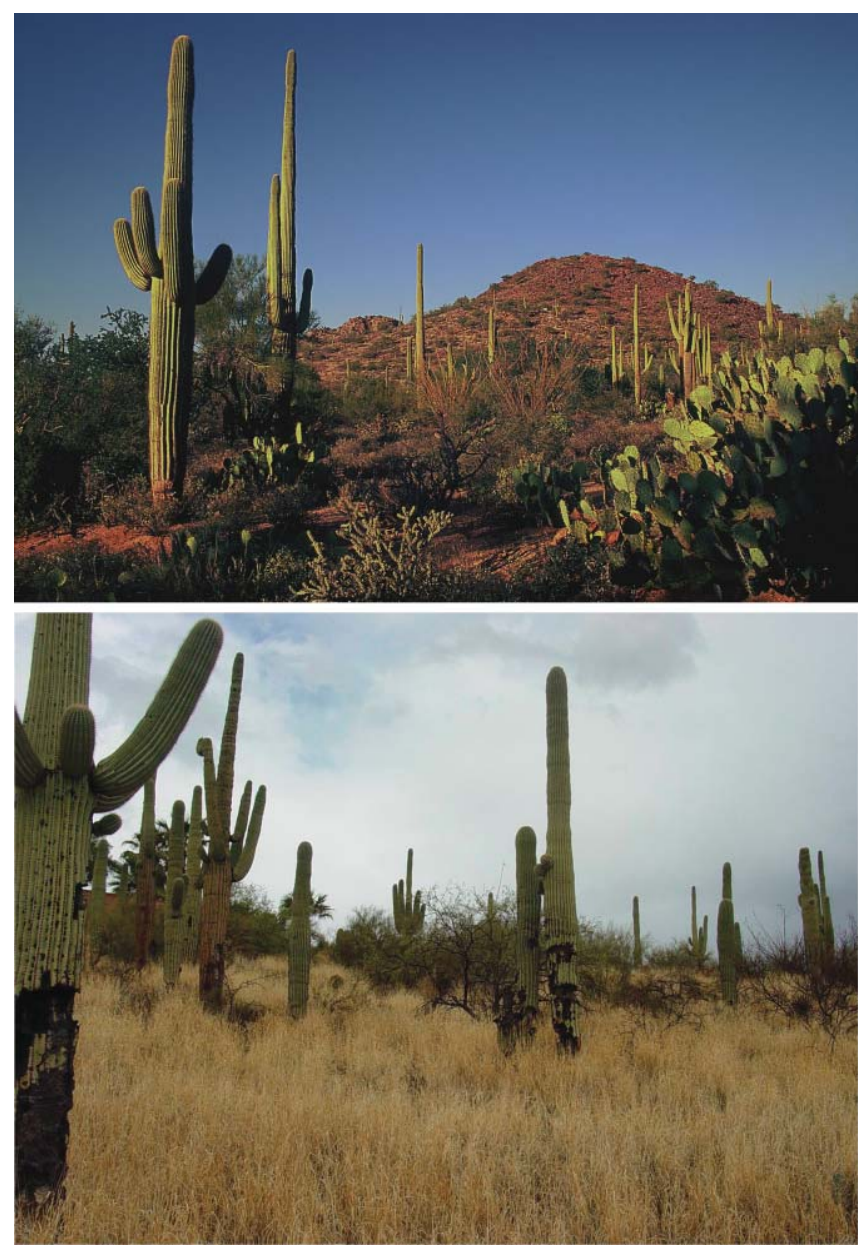

(top) Typical Sonoran Desert vegetation, which is poorly adapted to fire. Photo taken in the Saguaro National Park West, Tucson Mountains, Arizona. Photo courtesy Manny Rubio, 2006/ASDM Sonoran Desert Digital Library. (bottom) Buffelgrass invasion in the Sonoran Desert. Perennial buffelgrass forms dense stands, crowds out both annual and perennial native vegetation, and readily carries fire. Photo courtesy of Aaryn Olsson, University of Arizona.
(Olneya tesota A. Gray). About half of the Sonoran Desert flora are annuals, and in the Arizona Upland up to $80 \%$ are winter annuals. ${ }^{24}$

The biological diversity of the Sonoran Desert is threatened by the introduction of invasive species, cattle ranching, agricultural production, urbanization, groundwater depletion, mining, sand and rock extraction, catastrophic wildfires, and off-road recreational activities. Invasions by red brome (Bromus rubens L.), Schismus spp., and buffelgrass have been particularly harmful, because they carry fire. The perennial buffelgrass forms dense stands, crowds out both annual and perennial native plants, and readily carries fire in an ecosystem that is not fire adapted. ${ }^{25-28}$

\section{Setting the Stage}

The Wildfire and Invasive Plants in American Deserts conference highlighted key issues related to the combined threat of invasives and wildfire in hot deserts through a workshop comprising a number of presentations. The workshop began with a Southern Nevada Fire Complex Case Study presented by Karen Prentice, the Emergency Stabilization and Rehabilitation Coordinator for the Bureau of Land Management in Ely, Nevada. Due to its complex nature, the Southern Nevada Fire Complex provided a perfect overview of the challenges faced by land managers in the hot deserts. The Complex burned approximately 739,000 acres (299,063 ha) between June and July 2005, and was primarily fueled by annual invasive Bromus species. Rehabilitation efforts following the Complex Fire provided a number of lessons learned including 1) the need for a better understanding of the range of variation in vegetation response of desert plant communities, 2) the necessity for cross-jurisdictional communication so that technical and policy knowledge is shared, and 3) the use of a regional, landscape-level perspective when planning and implementing rehabilitation efforts.

Sandee Dingman, a Natural Resource Specialist for the National Park Service at Lake Mead in Nevada, suggested that the most critical component of an ideal approach to fire and invasive species management was a comprehensive Fire Management Plan (FMP) that establishes goals and identifies fire management activities that may promote native plant communities or nonnative and invasive species. The FMP should ideally include details of operational guidelines, locations of existing invasive species populations, strategies that may reduce the spread of invasive species, research and monitoring findings for local vegetation communities, and lessons learned from previous fires in the area.

An increase in invasive species that fuel wildfires is dramatically affecting the frequency and scale of fires now occurring in the hot deserts. These fires are now burning closer to urban populations and their associated infrastructure. The wildland-urban interface presents new challenges to land managers responsible for vast areas, especially in the hot deserts, which are experiencing some of the fastest 
population growth in the country, but have historically had infrequent fires. Julio Betancourt, a Senior Research Scientist with the US Geological Survey in Tucson, Arizona, suggested that the invasion of buffelgrass in southeastern Arizona presents challenges and opportunities. Many of the challenges are similar to those posed by other invasions, including increased fire risk, a greater financial burden on fire departments and agencies to protect lives and property, and a critical need for education and outreach. Although these challenges are great, there are also unique opportunities in wildland-urban interface areas that should be capitalized upon, including 1) engagement of civic leaders, the business community, and other stakeholders for better policy development; 2) a larger audience base for obtaining scarce resources for invasive species management; 3 ) the development of novel approaches for managing invasive species infestations; and 4) the availability of citizen scientist groups to participate in research and monitoring.

Regardless of the location, existing policies can either promote or hinder quality on-the-ground invasive species management, affecting the fire potential and risks associated with plant communities of the hot deserts. Travis Bean, Principal Research Specialist at the University of Arizona, identified policy-related roadblocks to invasive species management on large scales. Knowing the extent of the infestations, especially in relation to the distribution of critical resources, is one of the most important pieces of information a land manager can have. Definitive mapping of infestations and species distributions are critical for planning, control, and future management. Maps must be regularly updated to provide relevant information for achieving long-term goals. Generally, with invasive species management immediate action is necessary to keep costs down. The longer treatment is postponed, the larger the population and infestation expanse, and thus the more costly the treatment. Therefore, control efforts must start big and be scaled down as control is achieved. Lastly, budget stability is essential for making progress on controlling invasive species populations. Money used in early years for control treatments that are not monitored or followed with secondary treatments as necessary is essentially wasted if follow-up treatments are not possible because of the lack of resources in subsequent years.

\section{Recommendations}

Workshop participants were invited to provide additional comments and feedback following the speakers' presentations addressing two general questions: 1) What is the most critical issue, challenge, or goal that must be addressed in hot desert fire and invasive species management? and 2) What is the best strategy for success? A total of 156 participant responses, described in more detail below, were informative, specific, and varied in the identification of the most critical issues and successful strategies (Fig. 1).

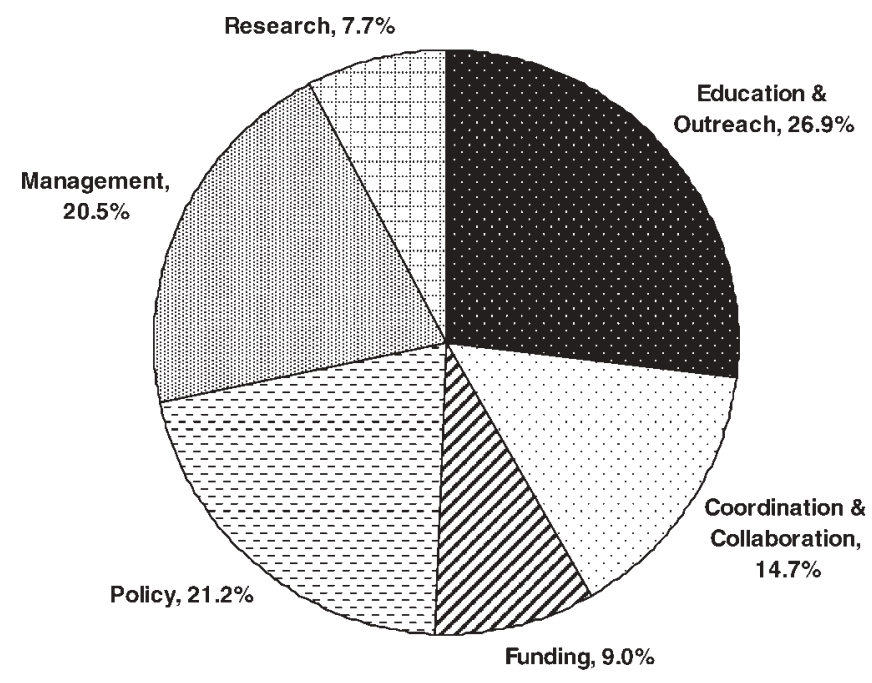

Figure 1. Critical issues identified by audience participation feedback for Workshop I: Hot Desert Fire and Invasive Species Management at the Wildfires and Invasive Plants in American Deserts Conference, Reno, Nevada, in December 2008.

\section{Management Essentials: Rehabilitation, Monitoring, and Fuels}

Management issues are widely varied, reflecting the diverse factors that must be taken into account when dealing with the often-novel situations imposed by invasive species. Successful management for effective control requires comprehensive monitoring of successes and failures, good data on occurrence and spread of the species, and strategies that take into account basic life history traits of the species and incorporate phenological modeling based on climate predictions. However, management does not end there. In the inevitability that some wildfires cannot be contained, it continues in the form of fuels management, the active control of fires, and the rehabilitation of infested or burned areas.

A selection of the major suggested management strategies included the following:

- Prioritize and target areas with high resource value for management (not just wildland-urban interface areas).

- Clearly define duties and responsibilities for different jurisdictions-from department of transportation management of both invasive and wildfire spread along road right-of-ways to individual landowners and homeowner's associations.

- Adjust expectations of the end result with respect to climate change.

- Base management responses on the ecosystem's fire regime and whether or not this has been changed by invasive species.

- Recognize that in a particular area, best management practices for rehabilitation may include doing nothing.

- Develop economic sustainability in seed markets and infrastructure for long-term seed storage, because seed availability is currently a limiting factor for rehabilitation. 
- Identify benchmarks and desired landscapes (goals) prior to initiating monitoring, and modify as necessary given variable climatic conditions.

- Use technology to guide monitoring efforts.

- Regularly monitor both burned and unburned areas, and use data to inform other aspects of invasive species management (policy, treatment, future rehabilitation, etc.).

- Monitor fuel management treatments for efficacy and share the resulting lessons learned through a centralized clearinghouse.

\section{Coordination and Collaboration}

Managing large landscapes necessitates the involvement of multiple stakeholders, and therefore coordination and collaboration become key components of any successful management activity. By working together, small groups can overcome challenges and experience large achievements by leveraging scarce resources. Urbanized areas face additional challenges, but are also presented with a variety of new opportunities to garner support of invasive species and wildfire prevention management actions.

A selection of strategies for better coordination and collaboration included the following:

- Share critical information pertaining to invasive species with fire managers via fire information packets during incidents, and promote and coordinate preventative efforts.

- Coordinate all aspects of the invasive species issue (fuel and fire management, research, rehabilitation, funding, and policy) at all levels, and share the information where applicable and possible through a centralized clearinghouse.

- Identify and engage stakeholders early; the collaboration process should include multiple jurisdictions and international partners, where appropriate.

- Strategize regionally and coordinate data sharing using existing tools (e.g., NASA/US Geological Survey's invasive species forecasting system).

- Utilize cross-jurisdictional invasive species or weed groups (Cooperative Weed Management Areas, Natural Resource Conservation Districts, etc.) to leverage funds for treatment activities.

- Share and update lessons learned through a centralized clearinghouse of data and related information.

\section{Education and Outreach}

Education and public outreach efforts are extremely costeffective tools that should be utilized to their best advantage. Engaging the public in the challenges faced by land managers is an important component of achieving lasting results. Stakeholders from all levels and sectors should be approached and addressed via creative means, including print materials, public presentations, volunteer opportunities, and media interactions. It is crucial to enlist public support of efforts to control invasive species by connecting the issues associated with invasive species and wildfire to peoples' everyday lives.

Suggestions for education and outreach (or public engagement) included the following:

- Identify and promote a champion or mascot that will make the invasive species-fire connection.

- Utilize existing programs (Cooperative Extension, Firewise, Adopt-a-Highway and Adopt-a-Trail Programs, etc.) to capitalize on and promote further public involvement.

- Conduct cross-jurisdictional education efforts at all levels ( $\mathrm{K}-12$, general public, civic leaders, and policy makers).

- Identify and support volunteer coordinators through existing youth service programs (AmeriCorps VISTA, Conservation Corps, etc.) and further promote and use these programs to enlist workers.

- Develop creative ways for all sectors of the public to participate in invasive species management.

- Motivate and encourage action using a variety of methods including rewards, ordinances, and penalties.

- Develop best management practices for small-scale action (i.e., a "toolkit" for homeowners' associations, scout troops, and others).

- Demonstrate and publicize all successful actions through a clearinghouse (similar to the Wildland Fire Lessons Learned Center).

\section{Research}

There are many unmet research needs that could greatly increase the effectiveness of management and help to guide the establishment of sound policy. Unfortunately, science often focuses on defining the impacts of invasive species in an ecosystem in order to make the case for their control. With invasive species and fire in hot deserts, there is a critical need for research focused on the effects and efficacy of management. A general laundry list of invasive species research needs includes remote sensing/mapping, economic analyses, Web-based decision support systems, spread and bioclimatic models, impacts of control treatments on rare species and critical habitats, restoration techniques, unintended consequences of chemical control, phenological and propagule pressure models, seed bank and dispersal ecology, soil nutrient dynamics, genetic studies, and biological control, among others.

Suggestions for research included the following:

- Explore the implications and consequences of large-scale and long-term treatments (herbicide application, manual removal, etc.) on the whole ecosystem.

- Study the postfire dynamics and ecosystem processes that have implications for rehabilitation of native ecosystems, especially under varying climate regimes.

- Determine the effectiveness and cost of various control techniques for species and environments. 
- Identify species that may be utilized for postfire rehabilitation under differing climate regimes.

\section{Policy Essentials and Prioritization}

As with many pressing environmental issues, policies influencing the management of invasive species in hot deserts have been almost entirely reactive instead of proactive. Perhaps this is because fires in these areas are a relatively recent occurrence in the history of human management, and thus have not necessitated active policy. Nevertheless, as invasions and fires increase in frequency and extent, the lack of a comprehensive public policy becomes a major stumbling block in the successful management of invasive species and fires in hot deserts. This causes countless other associated environmental and economic problems.

Suggested priorities for policy included the following:

- Promote invasive plant control as sustained public works projects that require training, an increased work force, and greater contractor capacity.

- Review and modify existing policies that hinder treatment.

- Perform cost-benefit analyses to attract the attention of policy makers and other stakeholders.

- Develop action plans with identified goals, objectives, and performance metrics for large landscapes (in prevention of and preparation for large-acre wildfires).

- Accept that mitigation and adaptation are two necessary components of long-term management. It is important to acknowledge that some areas cannot be "saved" and resources should be used where they are most effective.

\section{Funding}

As expected, the easy answer to addressing invasive species and wildfire concerns is to increase dedicated funding. However, in difficult local and national economic times with scant resources available, the concept of just increasing funding is generally not a feasible solution. Land managers and other stakeholders must be especially creative in developing alternative solutions to these complex issues using limited resources. Managers and funding entities must consider the possibility that aggressive funding early in the invasive-fire cycle may provide long-term savings by avoiding ongoing expenses related to the continual treatment of invasive plant populations that recover after insufficient or unsustained control efforts.

Suggested funding strategies included the following:

- Incorporate nonlinear growths, costs, and comparison associations with doing something today vs. later in all cost-benefit analyses.

- Increase and improve fund leveraging by collaboration and cooperation across multiple jurisdictions.

- Land managers and stakeholders provide information and support to decision makers prior to decisions for funding allocations.
- Consistently fund all aspects of invasive species management (mapping, public engagement, treatment, and monitoring).

- Demonstrate cost-effectiveness and share lessons learned through a centralized clearinghouse.

- Explore all alternative funding solutions including user fees and taxes, as well as grant and donor solicitations.

- Develop a template for successful funding mechanisms for small community-based groups, and make it available via a centralized clearinghouse.

- Prioritize target areas regionally for better utilization of scarce resources and funding allocations.

\section{Conclusion}

Managing an ever-changing landscape to control invasive species and the resulting increase in fire potential should be a high priority. One possible solution to many of the challenges and issues identified during this conference would be the creation or development of a national (or at least western US) interagency invasive species team that has the responsibility of coordinating information, treatment options, funding opportunities, and rehabilitation prior to, during, and after wildfires. This proposed team could comprise invasive species specialists who work closely with local invasive species specialists to identify opportunities for funding, early detection, and research. A centralized team can also quickly respond to wildfires as they occur, and can help Burned Area Emergency Response teams as they develop rehabilitation plans following incidents. The proposed team could be stationed at the National Interagency Fire Center (NIFC) in Boise, Idaho, or another centralized location, which may make it possible for decision makers and land managers to better capitalize on existing opportunities while creating new ones.

Advantages of hosting such a team at NIFC are many. First, created in 1965, NIFC is a proven national example for multijurisdictional wildland fire response coordination. Fire management agencies and those responsible for invasive species management are one and the same, so information regarding both invasive species infestations and fires would be more readily shared and utilized if it were easily accessible and available. Secondly, it would further promote active communication between the invasive species management and the fire management communities, which would allow for increasing public awareness of the close association of these two issues. The development of public outreach and education could also be streamlined and shared across deserts, with the possibility of having specialists available to respond immediately to fires who could also address invasive species concerns (trained public information officers, for example). Lastly, although there would still be a need for local knowledge, this team could serve as a clearinghouse of invasive species information (funding opportunities and strategies, research, rehabilitation options, and lessons learned) available to the land managers who need it most. 
Proactively addressing invasive species fuels in deserts would enable fire managers to address the frequency of fires in these ecosystems and allow them to prioritize areas of greatest impact overall. Even though the American deserts offer some of the most remote country and may be considered lower priority areas for response when multiple fires occur simultaneously, these ecosystems are being dramatically impacted by wildfires and will continue to be so as long as fire-promoting invasive species are present.

Policy makers, land managers, scientists, students, and the interested public do not have all the answers, nor do they have all the questions. Completing this process of synthesizing information from workshop presentations and audience response resulted in the identification of immediate critical issues and challenges facing the American hot deserts, and as with most natural resource management items, specific issues needing attention will change over time as a result of new species invasions, lessons learned through active management and responses, and natural processes. Therefore it is critical that information is shared across jurisdictions and at multiple levels to develop the best strategies for managing the unique deserts of the American Southwest.

\section{Acknowledgments}

The authors would like to thank the conference planning committee and conference sponsors for providing the opportunity to gather the data referenced and synthesized herein. The authors also thank Julio Betancourt and the conference synthesizing committee for their valuable comments on earlier versions of this article.

\section{References}

1. Cox, G. W. 1999. Alien species in North America and Hawaii: impacts on natural ecosystems. Washington, DC, USA: Island Press. 387 p.

2. Stohlgren, T. J., D. Brinkley, G. W. Chong, M. A. Kalkhan, L. D. Schell, K. A. Bull, Y. Otsuki, G. Newman, M. Bashrin, and Y. Son. 1999. Exotic plant species invade hot spots of native plant diversity. Ecological Monographs 69:25-46.

3. Deloach, C. J., R. I. Carruthers, J. E. Lovich, T. L. Dudley, And S. D. Smith. 2000. Ecological interactions in the biological control of saltcedar (Tamarix spp.) in the United States: toward a new understanding. In: N. R. Spencer (ED.). Proceedings of the $\mathrm{X}$ international symposium on biological control of weeds; 4-14 July 1999; Bozeman, MT, USA. Bozeman, MT, USA: Montana State University. p. 819-873.

4. Zavaleta, E. S., R. J. Новbs, and H. A. Mooney. 2001. Viewing invasive species removal in a whole-ecosystem context. Trends in Ecology and Evolution 16:454-459.

5. Osborn, S., V. Wright, B. Walker, A. Cilimburg, and A. Perkins. 2002. Linking wilderness research and management-volume 4. Understanding and managing invasive plants in wilderness and other natural areas: an annotated reading list. Fort Collins, CO, USA: US Department of Agriculture, Forest
Service, General Technical Report RMRS-GTR-79-Vol 4. $65 \mathrm{p}$.

6. Hoyt, C. A. 2002. The Chihuahuan Desert: diversity at risk. Endangered Species Bulletin XXVII(2):16-17.

7. Holmgren, C., J. Norris, and J. Betancourt. 2007. Inferences about winter temperatures and summer rains from the late Quaternary record of $\mathrm{C}_{4}$ perennial grasses and $\mathrm{C}_{3}$ desert shrubs in the northern Chihuahuan Desert. Journal of Quaternary Science 22:141-161.

8. Barnes, W. C. 1936. Herds in the San Simon Valley. American Forests 42:456-458.

9. Buffington, L. C., And C. H. Herbel. 1965. Vegetational changes on a semiarid desert grassland range from 1858 to 1963. Ecological Monographs 35:139-164.

10. Branson, F. A. 1985. Vegetation changes on western rangelands. Denver, CO, USA: Society for Range Management Range Monograph 2. 76 p.

11. Archer, S. 1989. Have southern Texas savannas been converted to woodlands in recent history? The American Naturalist 134:545-561.

12. Báez, S., And S. L. Collins. 2008. Shrub invasion decreases diversity and alters community stability in northern Chihuahuan Desert plant communities. PLoS ONE 3(6):e2332. doi:10.1371/journal.pone.0002332.

13. Fredrickson, E., K. M. Havstad, R. Estell, and P. Hyder. 1998. Perspectives on desertification: southwestern United States. Journal of Arid Environments 39:191-207.

14. Saunders, D. A., R. J. Нobbs, and C. R. Margules. 1991. Biological consequences of ecosystem fragmentation: a review. Conservation Biology 5:18-32.

15. Vickery, P. D., P. L. Tubaro, J. M. Da Silva, B. G. Peterjohn, J. G. Herkert, and R. B. Cavalcanti. 1999. Conservation of grassland birds of the Western Hemisphere. Studies in Avian Biology 19:2-26.

16. Desmond, M. J., K. E. Young, B. C. Thompson, R. Valdez, and A. Lafon Terrazas. 2005. Habitat associations and conservation of grassland birds in the Chihuahuan Desert region: two case studies in Chihuahua, Mexico. In: J. L. E. Cartron, G. Ceballos, and R. S. Felger (EDs.). Biodiversity, ecosystems, and conservation in northern Mexico. New York, NY, USA: Oxford University Press. p. 439-451.

17. Young, K. E., S. Schrader, G. Roemer, C. Caldwell, K. Boykin, H. Reiser, and A. Ernst. 2007. Early detection of invasive species in Big Bend National Park: remote sensing and GIS strategies, May. Available at: http://fws-nmcfwru. nmsu.edu/BIBE/. Accessed 23 January 2009.

18. Jaeger, E. C. 1955. The California deserts. Stanford, CA, USA: Stanford University Press. 205 p.

19. Western Ecological Research Center. 2002. Nonnative grass invasions and fire in the Mojave Desert. US Geological Service Factsheet, August. Available at: http://www.werc.usgs. gov. Accessed 15 January 2009.

20. DeFalco, L., D. R. Bryla, V. Smith-Longozo, and R. S. Nowak. 2003. Are Mojave Desert annual species equal? Resource acquisition and allocation for the invasive grass Bromus madritensis subsp. rubens (Poaceae) and two native species. American Journal of Botany 90:1045-1053.

21. Ezcurra, E., and V. Rodrigues. 1986. Rainfall patterns in the Grand Desierto, Sonora, México. Journal of Arid Environments 10:13-28. 
22. Brown, D. E. (ED.). 1994. Biotic communities: southwestern United States and northwestern Mexico. Salt Lake City, UT, USA: University of Utah Press. 342 p.

23. Turner, R. M., J. E. Bowers, and T. L. Burgess. 1995. Sonoran Desert plants: an ecological atlas. Tucson, AZ, USA: University of Arizona Press. 501 p.

24. Venable, D. L., and C. E. Pake. 1999. Population ecology of Sonoran Desert annual plants. In: R. H. Robichaux (ED.). The ecology of Sonoran Desert plants and plant communities. Tucson, AZ, USA: The University of Arizona Press. p. 115142.

25. Búrquez, A., and M. A. Quintana. 1994. Islands of diversity: ironwood ecology and the richness of perennials in a Sonoran Desert biological reserve. In: G. P. Nabhan and J. L. Carr (EDS.). Ironwood: an ecological and cultural keystone of the Sonoran Desert. Washington, DC, USA: Conservation International. $92 \mathrm{p}$.

26. Van Devender, T. R., and M. A. Dimmitt. 2000. Desert grasses. In: S. J. Phillips and P. W. Comus (EDs.). A natural history of the Sonoran Desert. Tucson, AZ, USA: ArizonaSonora Desert Museum Press, and Berkley and Los Angeles, CA, USA: University of California Press. p. 265-280.
27. Búrquez-Montijo, A., M. E. Miller, and A. MartínezYRízAR. 2002. Mexican grasslands, thornscrub, and the transformation of the Sonoran Desert by invasive exotic buffelgrass (Pennisetum ciliare). In: B. Tellman (ED.). Invasive exotic species in the Sonoran region. Tucson, AZ, USA: University of Arizona Press and Arizona-Sonora Desert Museum. p. 126146.

28. Rogstad, A. (ED.). 2008. Southern Arizona buffelgrass strategic plan: a regional guide for control, mitigation, and restoration. Tucson, AZ, USA: Buffelgrass Working Group. 204 p.

Authors are Science Coordinator and Invasive Species Program Manager, Center for Sonoran Desert Studies, Arizona-Sonora Desert Museum, 2021 N Kinney Rd, Tucson, AZ 85743, USA (Rogstad); Principal Research Specialist, School of Natural Resources, University of Arizona, Tucson, AZ 85719, USA, bean@email.arizona.edu (Bean); Senior Research Specialist (Olsson), and Assistant Research Specialist (Casady), Arizona Remote Sensing Center, Office of Arid Lands Studies, University of Arizona, Tucson, AZ, USA. 